\title{
An alternative semiparametric approach to the modelling of asymmetric gasoline price adjustment
}

\author{
Michael L. Polemis ${ }^{\mathrm{a} 1}$ and Mike G. Tsionas ${ }^{\mathrm{b}}$
}

\begin{abstract}
In this paper we revisit the wholesale and retail gasoline price adjustments to fluctuations in the input cost prices for a monthly panel dataset of 48 U.S. states over the period 1994 to 2011. In doing so, we employ non-linear semiparametric models with local Generalized Method of Moments (GMM) estimators. Our findings indicate that wholesale and retail gasoline prices adjust more rapidly in an upward than a downward direction, confirming the "rockets and feathers" hypothesis.
\end{abstract}

\section{JEL classification: L13, C5, C13}

Keywords: Semiparametric GMM model; Asymmetric gasoline price adjustment; Rockets and feathers hypothesis.

\footnotetext{
${ }^{a}$ Department of Economics, University of Piraeus, Piraeus, 185 34, Greece (Corresponding author). Tel: +30 210 4142303; Fax: +30 210 4142346; Email: mpolemis@unipi.gr.

${ }^{\mathrm{b}}$ Department of Economics, Lancaster University Management School, LA1 4YX, United Kingdom and Department of Economics, Athens University of Economics and Business, Athens 104 34, Greece.
} 


\section{Introduction}

There is a common belief among consumers indicating that oil companies adjust the retail gasoline prices and their profit margins more quickly to cost increases than to cost decreases. This behaviour is broadly known as the "rockets and feathers" hypothesis (Bacon, 1991). Within the last years there is a plethora of studies examining the existence and the causes of gasoline price asymmetry with controversial results. The majority of these studies (Lewis and Noel, 2011, Deltas, 2008, Chen et al, 2005) apply cointegration techniques and Engle-Granger methodology. However, recent studies such as Greenwood-Nimmo and Shin, (2013) depart from the standard strand of literature in allowing non-linear functional forms.

Many important papers have tried to investigate the existence of price asymmetry across countries or even regions with conflicting results. Bacon (1991), for example, provided sufficient evidence in favor of the price asymmetry debate in the UK. Similarly, Borenstein et al. (1997) argued that retail prices in the UK over the period 1986 to 1992 responded more quickly to crude oil price increases than to decreases. Galeotti et al. (2003) studied trends in Germany, France, UK, Italy and Spain from January 1985 to June 2000 and concluded that "rockets and feathers" appear to dominate the price adjustment mechanism of gasoline markets in many European countries. Deltas (2008) reported that U.S. states with high average retail-wholesale margins experienced a slower adjustment and a more asymmetric response in retail prices. Lewis and Noel (2011) use panel data from U.S. cities with and without Edgeworth price cycles, and demonstrate that prices in markets without cycles respond much more slowly to wholesale cost fluctuations than in cities with cycles. 
Greenwood-Nimmo and Shin (2013), in contrast, did not support the existence of "rockets and feathers" in the UK gasoline market. Similarly, Lamotte et al (2013) argued that the retail price of gasoline in the U.S and France respectively did not respond contemporaneously to crude oil shocks.

Despite the rich body of literature, existing studies suffer from two major limitations. First, they assume that asymmetric price responsiveness is apparent in a linear form. However, this is a rather strong assumption which may lead to biased results (Shin et al, 2013). Second and most importantly, nearly all of the existing empirical studies assume specific functional forms for their regression relationships. In other words they adopt parametric regression models that often lead to misspecification of their functional form unless it is correctly specified by the economic theory (Tran and Tsionas, 2009). In order to overcome this problem, we rely on panel data semiparametric methodology where little prior restriction is imposed on the model's structure. We further extend the existing semiparametric panel data models (see for example Li and Stengos, 1996, Knieser and Li, 2002, Baltagi and Li, 2002) by allowing for the regression coefficients on the parametric part to vary according to the smooth coefficient model. This may lead to more plausible empirical results (Tran and Tsionas, 2009).

The aim of this paper is to revisit the "rockets and feathers" hypothesis focusing on the role of inventories and using a semiparametric GMM approach. Our findings are consistent with an asymmetric wholesale and retail gasoline price pass through. The remainder of this paper is organized as follows. The next section describes the empirical model and the semiparametric modeling approach. The following two 
sections discuss the dataset used for the analysis and the empirical findings. Finally, the last section reports some concluding remarks.

\section{The econometric model}

Extending Greenwood-Nimmo and Shin (2013) to a panel data framework the model is based on an asymmetric nonlinear autoregressive distributed lag model (expressed in levels) as:

$$
y_{i t}=\sum_{j=1}^{p} \psi_{j} y_{t-j}+\sum_{j=0}^{q}\left(x_{i, t-j}^{+} \delta_{j}^{+}+x_{i, t-j}^{-} \delta_{j}^{-}\right)+e_{i t}
$$

where $\psi_{\mathrm{j}}$ are the autoregressive parameters, $\mathbf{x}_{i t}$ is a vector of regressors of dimension

$\left(\mathrm{p} \times 1\right.$ ) with its first element $x_{i t, 1}=1, \quad \mathbf{x}_{i t}^{+}=\sum_{j=1}^{t} \max \left(\Delta \mathbf{x}_{i j}, 0\right)$, $\mathbf{x}_{i t}^{-}=\sum_{j=1}^{t} \min \left(\Delta \mathbf{x}_{i j}, 0\right)$ are partial sum processes representing positive and negative changes respectively. We allow some or all components of $x_{i t}$ to be correlated with the error $\mathrm{e}_{\mathrm{it}}$. We also assume the data to be independent across the $i$ index but there is no restriction on the time index $t$. The coefficients $\delta_{j}^{+}$and $\delta_{j}^{-}$contain the positive and negative asymmetric distributed-lag parameters respectively, and finally $\mathrm{e}_{\mathrm{it}}$ is an i.i.d. process. According to Granger representation theorem, the associated error correction model (ECM) is given by the following equation:

$$
\Delta y_{i t}=\rho y_{i, t-1}+x_{i, t-j}^{+} \delta_{j}^{+}+x_{i, t-j}^{-}{ }^{\prime} \delta_{j}^{-}+\sum_{j=1}^{p-1} \gamma_{j} \Delta y_{t-j}+\sum_{j=0}^{q-1}\left(\Delta x_{i, t-j}^{+}{ }^{\prime} \psi_{j}^{+}+\Delta x_{i, t-j}^{-}{ }^{\prime} \psi_{j}^{-}\right)+e_{i t}
$$

Where $\rho=\sum_{j=1}^{p} \psi_{j}-1, \gamma_{j}=-\sum_{i=j+1}^{p} \psi_{j}, \delta^{+}=\sum_{j=0}^{q} \delta_{j}^{+}, \delta^{-}=\sum_{j=0}^{q} \delta_{j}^{-}, \psi_{0}^{+}=\delta_{0}^{+}$, 
$\psi_{0}^{-}=\delta_{0}^{-}, \psi_{j}^{+}=-\sum_{i=j+1}^{q} \delta_{j}^{+}, \psi_{j}^{-}=-\sum_{i=j+1}^{q} \delta_{j}^{-}, \alpha^{+}=-\frac{\delta^{+}}{\rho}$ and $\alpha^{-}=-\frac{\delta^{-}}{\rho}$ represent the asymmetric long-run parameters.

From Eq. 2, we can easily construct the following conditional Panel Vector-ErrorCorrection Model (PVECM):

$$
\begin{gathered}
\Delta y_{i t}=\rho y_{i, t-1}+\mathbf{x}_{i, t-1}^{+} \delta^{+}+\mathbf{x}_{i, t-1}^{-}{ }^{\prime} \delta^{-}+\sum_{j=1}^{p-1} \gamma_{j} \Delta y_{i, t-j}+ \\
\sum_{j=0}^{q-1}\left(\Delta \mathbf{x}_{i, t-j}^{+}{ }^{\prime} \pi_{j}^{+}+\Delta \mathbf{x}_{i, t-j}^{-}{ }^{\prime} \pi_{j}^{-}\right)+e_{i t}
\end{gathered}
$$

Short-run symmetry requires:

$$
\pi_{j}^{+}=\pi_{j}^{-}, \forall j=0, \ldots, q-1
$$

or alternatively:

$$
\sum_{j=0}^{q-1} \pi_{j}^{+}=\sum_{j=0}^{q-1} \pi_{j}^{-}
$$

We use the varying-coefficients approach to model (3) in a non-parametric way. For simplicity in notation, we write (3) as:

$$
Y_{i t}=x_{i t}^{\prime} d\left(z_{i t}\right)+e_{i t}
$$

where $Y_{i t}=\Delta y_{i t}, \mathbf{x}_{i t}$ is the vector of right-hand-side variables in (3), $\mathbf{z}_{i t}$ is a vector of predetermined variables and $d$ represents the coefficients. Notice that the adjustment coefficients $\gamma_{j}$ are not assumed to be fixed (Fan and Zhang, 1999). Moreover suppose $Y_{i}=\left(Y_{i t}, t=1, \ldots, T\right), X_{i}$ is a matrix whose rows are $x_{i t}{ }^{\prime}$ and $Z_{i}$ is a matrix whose rows are $z_{i t}{ }^{\prime}$. We assume there are instruments $w_{i t}$ and $W_{i}$ is a matrix whose rows are 
$w_{i t}^{\prime}$. We assume that $\left(X_{i}, Z_{i}, W_{i}, u_{i}\right)$ are i.i.d over $i=1, \ldots, n$ and $E\left(w_{i t} u_{i t} \mid z_{i t}\right)=0, " t=1, \ldots, T$

which implies that for given $z_{i t}=z$ we have:

$$
E\left(W_{i}^{\prime} u_{i} \mid Z_{i}=i_{T} z^{\prime}\right)=\varepsilon_{t=1}^{T} E\left(w_{i t} u_{i t} \mid z_{i t}=z\right)=0
$$

where $i_{T}=(1, \ldots 1)$ ' is a vector of ones. From Tran and Tsionas (2009) we know that identification requires that $E\left(W_{i}^{\prime} X_{i} \mid Z_{i}=i_{T} z^{\prime}\right)$ has full column rank. Since we have conditional moment restrictions that can be used to construct an estimator similar to the GMM, our objective criterion is

$$
J_{n}(d)=\left[\frac{1}{n}\left(Y-X d(z)^{\prime}\right) K W\right] R_{n}^{-1}\left[n^{-1} W^{\prime} K(Y-X d(z))\right]
$$

where $Y=\left(Y_{1}{ }^{\prime}, \ldots, Y_{n}{ }^{\prime}\right)^{\prime}$ is a $(\mathrm{NT} \times 1)$ vector, $W=\left(W_{1}{ }^{\prime}, \ldots, W_{n}{ }^{\prime}\right)^{\prime}$ is $(\mathrm{NT} \times 1)$ matrix of instruments,$X=\left(X_{1}{ }^{\prime}, \ldots, X_{n}{ }^{\prime}\right)$ is a (NT x p) matrix of regressors, $\mathrm{R}_{\mathrm{n}}$ is some $(1 \times 1)$ positive definite weighting matrix and $\mathrm{K}$ is an (NT $\mathrm{x}$ NT) matrix of kernel weights with $K=\operatorname{diag}\left(K_{H}\left(z_{i t}-z\right)\right), \quad t=1, \ldots, T$ is a $(\mathrm{T} \quad \mathrm{x} \quad \mathrm{T})$ matrix and $\mathrm{K}_{\mathrm{H}}(\xi)=$ $\prod_{j=1}^{q} h_{j}^{-1} k\left(\xi_{j} / h_{j}\right)$, in which $k(\phi) \geq 0$ is a bounded univariate symmetric function with $\quad \int_{q} k(\phi) d \phi=1, \quad \int \phi^{2} k(\phi) d \phi=\omega>0, \quad \int k^{2}(\phi) d \phi=u>0, \quad$ so $\quad$ that $K(\xi)=\prod_{j=1}^{q} k\left(\xi_{j}\right)$, and $H=\operatorname{diag}\left\{h_{1}, \ldots, h_{q}\right\}$ is a (q $\times$ q) matrix of bandwidths with $|H|=\prod_{j=1}^{q} h_{j}$ and $\mathrm{h}_{\mathrm{j}}>0$.

For given $z_{i t}=z$ minimizing $J_{n}(d)$ yields the following estimator: 
$\hat{d}(z)=\left(X^{\prime} K W R_{n}^{-1} W^{\prime} K X\right)^{-1} X^{\prime} K W R_{n}^{-1} W^{\prime} K X$

To make the estimator operational we need an estimate of $R_{n}$. In the one-step version of Tran and Tsionas (2009) if we use $R(z)=E\left(W_{i}{ }^{\prime} K_{i}^{T} W_{i}\right)$ we have the estimator in closed form:

$\hat{d}(z)=\left[X^{\prime} K W\left(W^{\prime} K W\right)^{-1} W^{\prime} K X\right]^{-1} X^{\prime} K W\left(W^{\prime} K W\right)^{-1} W^{\prime} K Y$

where use is made of the consistent estimator $\hat{R}_{1 n}=n^{-1} \varepsilon_{i=1}^{n} W_{i}^{\prime} K_{i}^{T} W_{i}$. As mentioned by Tran and Tsionas (2009, p. 44): “Also, it is interesting to note that the one-step local GMM estimator given in (6) is numerically equivalent to the two-stage smooth coefficient least squares estimator (Li et al., 2002) where in the first stage, a smooth coefficient least squares regression of $X$ on $W$, yielding prediction $\hat{X}$, and in the second stage, a smooth coefficient least squares regression of $Y$ on $\hat{X}$ using the same kernel $K$ and bandwidth $H$.”

We follow the procedure in Tran and Tsionas (2009) for bandwidth and kernel selections. In the vector of instruments $\mathbf{w}_{i t}$ we include two lags of the dependent variable (Retail and wholesale gasoline prices respectively) and regressors (i.e spot gasoline prices, crude oil prices, gross profit margin and motor gasoline stocks) following the spirit of the standard dynamic GMM procedure (Arellano and Bond, 1991; Arellano and Bover, 1995). We use a standard normal kernel for $k(\cdot)$ and since $Z_{i t}$ is a scalar, univariate cross validation bandwidth selection procedure is used to determine the optimal bandwidth. For the selection of the instruments, we use the optimal instrument discussed in Baltagi and Li (2002). Specifically, we use the density-weighted kernel estimates of $\left\{\mathrm{E}\left(\mathrm{y}_{\mathrm{it}-1} \mid \mathrm{z}_{\mathrm{it}-1}\right), \mathrm{E}\left(\mathrm{y}_{\mathrm{it}-2} \mid \mathrm{z}_{\mathrm{it}-2}\right), \mathrm{E}\left(\mathrm{k}_{\mathrm{it}} \mid \mathrm{z}_{\mathrm{it}}\right), \mathrm{E}\left(\mathrm{k}_{\mathrm{it}-1} \mid\right.\right.$ $\left.\left.\mathrm{z}_{\mathrm{it}-1}\right), \mathrm{E}\left(\mathrm{n}_{\mathrm{it}} \mid \mathrm{z}_{\mathrm{it}}\right), \mathrm{E}\left(\mathrm{n}_{\mathrm{it}-1} \mid \mathrm{z}_{\mathrm{it}-1}\right)\right\}$ as instrument set for $\left\{\mathrm{y}_{\mathrm{it}-1}, \mathrm{k}_{\mathrm{it}}, \mathrm{n}_{\mathrm{it}}\right\}$. 


\section{Data}

The sample includes 48 U.S. states over the period from January 1994 to February 2011. All price variables (i.e Retail and wholesale-rack motor gasoline prices, spot gasoline and crude oil prices) are taken from the Energy Information Administration (EIA). Moreover, we calculate the gross profit margin, in order to capture the presence of market power (Deltas, 2008). Lastly, we use motor gasoline stocks that are usually ignored by the existing literature in order to account for the presence of inventory capacity (Borenstein and Shepard, 1992). Figure 1 depicts the relatively close co movement between the spot gasoline price and the level of gross profit margin. It is evident that gasoline prices were characterized by high volatility within the examined period, giving an indication of an asymmetric price pass trough.

Figure 1: Gasoline prices and profit margin (USD/gallon)

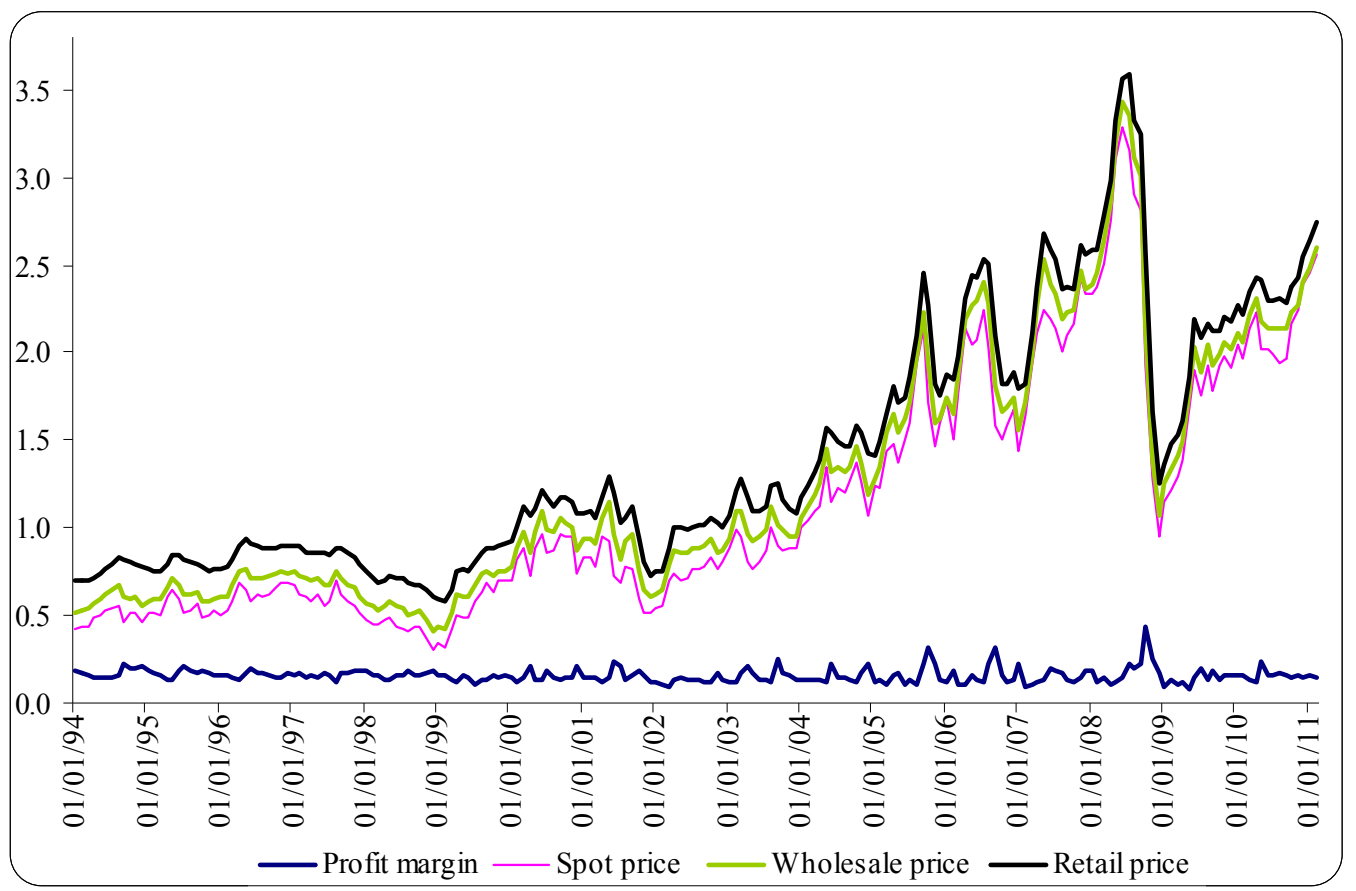

Source: EIA 


\section{Results and discussion}

Table 1 depicts the empirical findings. We report results at $z_{i t}=\bar{z}$ where $\bar{z}$ is the average of $z_{i t}$. It is evident that all the estimated coefficients are statistically significant at $\mathrm{a}=0.01$. Moreover, in both market segments positive coefficients are larger, in absolute value, than their negative counterparts indicating that the effects of upstream price increases are larger than those of price decreases ${ }^{2}$. Regarding the wholesale segment, it is highlighted that the speed of adjustment to positive input cost fluctuations is rather sluggish at $59 \%-60 \%$ per month. This means that if the wholesale price of gasoline is $10 \%$ above its long-run equilibrium price, the percentage change difference over a period of one month will be $5.8 \%$ and $6.0 \%$ respectively. However, in the retail segment, the speed of adjustment to the long-run equilibrium is characterised by larger variation reaching its peak at $70 \%$. This finding indicates that the level of retail competition varies significantly between the two market segments. Moreover, we find long-run coefficients $\left(\alpha^{+}\right.$and $\left.\alpha^{-}\right)$equal to 0.9 approximately for both wholesale and retail market segments. The relatively high value shows a clear indication that a long-run rent-seeking oligopolistic behaviour is present by the oil companies, which in turns is consistent with an asymmetric gasoline price adjustment mechanism at least in the long run.

In addition, the short-run price effect $\left(\pi_{0}^{+}\right.$and $\left.\pi_{0}^{-}\right)$is larger in the retail than in the wholesale segment with estimated values approaching 0.477 compared to 0.307 respectively. This means that retail gasoline prices seem to react more to price increases and to negative gaps to the equilibrium than to price decreases and positive

\footnotetext{
${ }^{2}$ The estimated results do not significantly change compared to a parametric estimation of Equation 3. The parametric results are available from the authors upon request.
} 
disequilibrium. From the magnitude of the relevant estimates, we argue that a $10 \%$ short-run increase in spot gasoline price will tend to increase the wholesale price of gasoline by about $3.0 \%-3.2 \%$ approximately. Lastly, if we try to compare the twomarket segments, some important features emerge. First, the magnitude of short-run coefficients is in the most cases larger in the retail than in the wholesale level. This means that retailers do immediately transfer onto final prices all the adjustments in the spot gasoline prices. Second, the adjustment towards the equilibrium level is more gradual in the wholesale level revealing the differences between the two market segments. 
Table 1. Non-parametric effects evaluated at the means $\bar{z}$ of $z_{i t}$

\begin{tabular}{|c|c|c|c|c|}
\hline \multirow[t]{2}{*}{$\begin{array}{l}\text { Estimated } \\
\text { coefficients }\end{array}$} & \multicolumn{2}{|c|}{$\begin{array}{c}\text { Spot gasoline price } \\
\text { Panel A }\end{array}$} & \multicolumn{2}{|c|}{$\begin{array}{c}\text { Crude oil price } \\
\text { Panel B }\end{array}$} \\
\hline & Wholesale & Retail & Wholesale & Retail \\
\hline$\rho$ & $\begin{array}{l}-0.588^{* * *} \\
(0.021)\end{array}$ & $\begin{array}{c}-0.644^{* * *} \\
(0.017)\end{array}$ & $\begin{array}{c}-0.603^{* * *} \\
(0.018)\end{array}$ & $\begin{array}{r}-0.701^{* * *} \\
(0.015)\end{array}$ \\
\hline$\alpha^{+}$ & $\begin{array}{l}0.913^{* * *} \\
(0.012)\end{array}$ & $\begin{array}{l}0.920^{* * *} \\
(0.013)\end{array}$ & $\begin{array}{l}0.910^{* * *} \\
(0.011)\end{array}$ & $\begin{array}{l}0.919^{* * *} \\
(0.009)\end{array}$ \\
\hline$\alpha^{-}$ & $\begin{array}{l}0.865^{* * *} \\
(0.043)\end{array}$ & $\begin{array}{l}0.907^{* * *} \\
(0.017)\end{array}$ & $\begin{array}{l}0.882^{* * *} \\
(0.033)\end{array}$ & $\begin{array}{l}0.932^{* * *} \\
(0.017)\end{array}$ \\
\hline$\pi_{0}^{+}$ & $\begin{array}{l}0.307^{* * *} \\
(0.027)\end{array}$ & $\begin{array}{l}0.435^{* * *} \\
(0.032)\end{array}$ & $\begin{array}{l}0.318^{* * *} \\
(0.025)\end{array}$ & $\begin{array}{l}0.477^{* * *} \\
(0.020)\end{array}$ \\
\hline$\pi_{0}^{-}$ & $\begin{array}{l}0.201^{* * *} \\
(0.030)\end{array}$ & $\begin{array}{l}0.355^{* * *} \\
(0.044)\end{array}$ & $\begin{array}{l}0.277^{* * *} \\
(0.025)\end{array}$ & $\begin{array}{l}0.400^{* * *} \\
(0.028)\end{array}$ \\
\hline$\sum_{\mathrm{j}=1}^{\mathrm{q}-1} \pi_{\mathrm{j}}^{+}$ & $\begin{array}{l}0.803^{* * *} \\
(0.018)\end{array}$ & $\begin{array}{l}0.900^{* * *} \\
(0.022)\end{array}$ & $\begin{array}{l}0.825^{* * *} \\
(0.019)\end{array}$ & $\begin{array}{l}0.930^{* * *} \\
(0.044)\end{array}$ \\
\hline$\sum_{\mathrm{j}=1}^{\mathrm{q}-1} \pi_{\mathrm{j}}^{-}$ & $\begin{array}{l}0.787^{* * * *} \\
(0.005)\end{array}$ & $\begin{array}{l}0.813^{* * *} \\
(0.011)\end{array}$ & $\begin{array}{l}0.884^{* * *} \\
(0.006)\end{array}$ & $\begin{array}{l}0.887^{* * *} \\
(0.007)\end{array}$ \\
\hline
\end{tabular}

Note: The table reports non-parametric marginal effects. Asymptotic standard errors are reported in parentheses. Results are reported using both Spot (Panel A) and Crude oil price (Panel B) in the Wholesale / Retail market segment respectively. Significant at ${ }^{* * *} 1 \%$.

Figure 2 plots the accumulated generalized impulse responses (GIR) of inventories to fluctuations in spot gasoline prices over a three month period. The GIR can be defined as the difference of two forecasts (Koop et al, 1996) indicated by the following expression:

$\operatorname{GIR}\left(t, s, d_{i}\right)=E\left(Y_{i, t+s} \mid v_{i t}=d_{i t} ; X_{i, t+s}\right)-E\left(Y_{i, t+s} \mid v_{i t}=0 ; X_{i, t+s}\right), s=0,1,2, \ldots$ 
where $d_{i}$ represents the value of the shock $e_{i t}$ and $X_{i t}$ represent other variables in the non-parametric regression. ${ }^{3}$ As it is evident, we observe a strong and rapid reaction of inventories to positive changes but a more gradual response to negative changes. It is clear that a $10 \%$ increase (decrease) in the spot gasoline price is associated with a maximum average increase and a moderate decrease (nearly 5-6\%) in the level of motor gasoline stocks respectively. This happens because retailers will almost immediately adopt new gasoline price by restoring the excess capacity and release it to the market in higher prices (Borenstein and Shepard, 1992). This behaviour provides a solid illustration of the "rockets and feathers" hypothesis in the U.S. gasoline market.

Figure 2. Accumulated generalized impulse responses to $10 \%$ increase and decrease in the spot gasoline price.

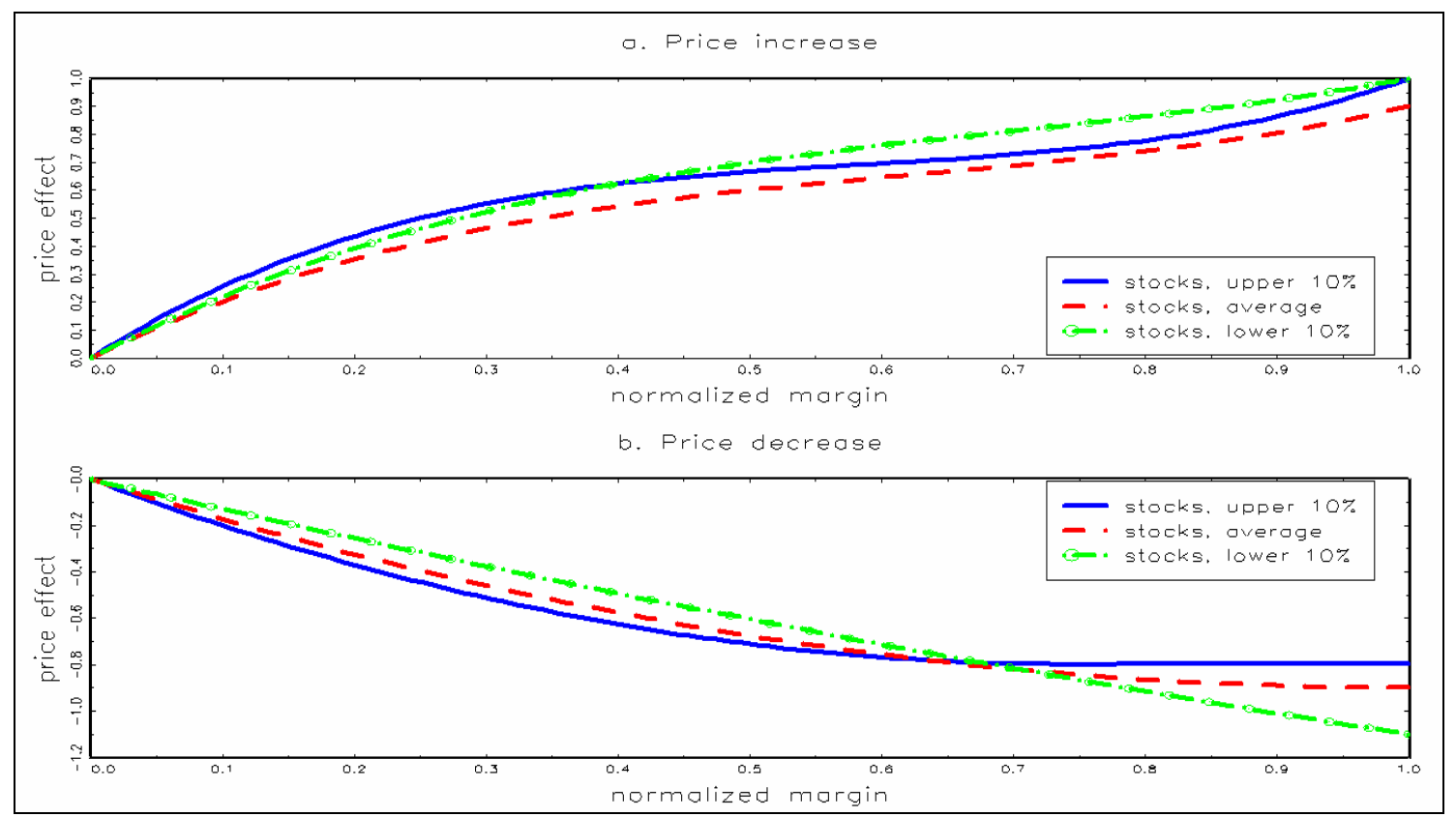

Note: Margin is normalized to lie between min and max denoted by 0 and 1 respectively. The vertical axis is normalized so that $10 \%=1.0$. Tick marks on the horizontal axis represent three-month intervals.

\footnotetext{
${ }^{2}$ Similar findings are also traced when we examine the GIR generated in the wholesale market segment by fluctuations in the crude oil price.
} 
To contextualize these findings, we draw comparisons with Deltas (2008), a study which linearly evaluates the effects of market structure through interacting lagged wholesale and retail price changes with state specific margins. Deltas (2008) finds coefficient estimates of response differences for wholesale price changes to be positive, indicating a faster response to price increases than decreases, indicating retail price asymmetry. His results also reveal that both the speed of adjustment and the degree of asymmetry depend on the average retail-wholesale margin of a state. He claims that states with large average profit margins tend to have more asymmetric and slower adjustment than states with small margins. Our empirical findings are in alignment with the aforementioned study revealing an asymmetric response of gasoline price to crude oil and spot price fluctuations. However, Deltas (2008) did not split the sample into high and low margin states by using a threshold analysis and allow for dynamic interactions of wholesale and retail gasoline price to input cost shocks (e.g crude oil price). Instead following the specifications of Borenstein and Shepard, 1996, Borenstein et al, (1997) and lastly Lewis, (2003), he used a linear lag adjustment model with an error correction term in order to investigate wholesale and retail price asymmetries. As described above, a linear ECM suffers from estimation uncertainty or errors arising from the estimation of the long run cointegrating relationship (Greenwood-Nimmo and Shin, 2013). In this study we address this limitation by the estimation of a threshold PVECM and subsequent PGIRFs that help us to assess the timing and magnitude of the responses to one time demand or supply shocks in the spot gasoline market (Kilian and Park, 2009; Kapetanios and Tzavalis, 2010). Lastly, by using a threshold (sample splitting) PVECM, we treated all our variables as endogenous with the inclusion of an exogenous threshold variable in 
contrast to the above study which require that all right-hand-side variables are strictly exogenous.

\section{Concluding remarks}

Using the NPGMM framework, we have found strong evidence suggesting the validity of the "rockets and feathers" hypothesis in the U.S gasoline market. Further, we infer that an input cost price increase is passed through more forcefully than a price decrease revealing a rent-seeking oligopolistic behaviour by the oil companies. The oligopolistic structure of the local gasoline markets along with fluctuations in both unanticipated shocks in spot gasoline price and inventories trigger the price asymmetric adjustment path.

\section{Acknowledgments}

We would like to thank two anonymous referees of this journal for their fruitful comments and suggestions that helped us improve our paper both in substance and presentation. Any remaining errors belong solely to the authors. Usual disclaimer applies. 


\section{References}

Arellano, M., and S. Bond. (1991). Some tests of specification for panel data: Monte Carlo evidence and an application to employment equations. Review of Economic Studies 58: 277-297.

Arellano, M., and O. Bover. (1995). Another look at the instrumental variable estimation of error-components models. Journal of Econometrics 68: 29-51.

Bacon, R.W. (1991). Rockets and Feathers: The Asymmetric Speed of Adjustment of UK Retail Gasoline Prices to Cost Changes, Energy Economics 13, 211 - 218.

Baltagi, B. H., Li, Q. (2002). On instrumental variable estimation of semiparametric dynamic panel data models. Economics Letters 76:1-9.

Borenstein, S, Cameron, C. A. and R. Gilbert (1997). Do Gasoline Prices Respond Asymmetrically to Crude Oil Price Changes?, Quarterly Journal of Economics 112 305-39.

Borenstein, S. and Shepard, A. (1992). Sticky Prices, Inventories and Market Power in Wholesale Gasoline Markets. RAND Journal of Economics, 33(1), 116-139.

Borenstein, S. and Shepard, A. (1996). Dynamic Pricing in Retail Gasoline Markets, RAND Journal of Economics, Vol. 27, pp. 429-451.

Chen, L, Finney, M., and Lai, K (2005) A threshold cointegration analysis of asymmetric price transmission from crude oil to gasoline prices. Economics Letters 89 (2), 233-239.

Deltas, G, (2008). Retail Gasoline Price Dynamics and Local Market Power, Journal of Industrial Economics 56, 613-28. 
Fan, J. and Zhang, W. (1999). Statistical estimation in varying coefficient models. Annals of Statistics. 27, 1491-1518.

Galeotti, M, L, Alessandro, and Manera, M (2003). Rockets and Feathers Revisited: An International Comparison on European Gasoline Markets, Energy Economics 25, 175-190.

Greenwood-Nimmo, M. and Y. Shin. (2013). Taxation and the Asymmetric Adjustment of Selected Retail Energy Prices in the UK, Economics Letters, 121, 411416.

Kilian, L. and Park, C. (2009). The Impact of Oil Price Shocks on the U.S. Stock Market, International Economic Review, 50, 267-1287.

Knieser, T. J., Li, Q. (2002). Nonlinearity in dynamic adjustment: semiparametric estimation of panel labor supply. Empirical Economics 27:131-148.

Koop G., M. H. Pesaran, and S. M. Potter (1996). Impulse Response Analysis in Nonlinear Multivariate Models. Journal of Econometrics 74, 119-147.

Lamotte, Olivier, Porcher, Thomas, Schalck, Christophe, and Silvestre, S, (2013) Asymmetric Gasoline Price Responses in France, Applied Economics Letters 20, 457 461

Lewis, M. (2003). Asymmetric Price Adjustment and Consumer Search: An Examination of the Retail Gasoline Market. UCEI Centre for the Study of Energy Markets Working Paper No. 120, University of California at Berkeley, California, U.S.A. 
Lewis, M., and Noel., M, (2011). The Speed of Gasoline Price Response in Markets with and without Edgeworth Cycles, The Review of Economics and Statistics 93, $672-682$.

Li, Q., Huang, C., Li, D., Fu, T.-T. (2002). Semiparametric smooth coefficient models. Journal of Business and Economic Statistics 20:412-422.

Li, Q., Stengos, T. (1996). Semiparametric estimation of partially linear panel data models. Journal of Econometrics 71:389-397.

Shin, Y., Yu, B., Greenwood-Nimmo, M.J., 2013. Modelling asymmetric cointegration and dynamic multipliers in a nonlinear ARDL framework. In: Horrace,

Tran, K., and E.G. Tsionas (2009). Local GMM estimation of semiparametric panel data with smooth coefficient models, Econometric Reviews 29 (1), 39-61.

Kapetanios, G. and Tzavalis, E., (2010). Modeling structural breaks in economic relationships using large shocks, Journal of Economic Dynamics and Control, 34(3), 417-436.

William, C., Sickles, Robin, C. (Eds.), Festschrift in Honor of Peter Schmidt. Springer Science and Business Media, New York. 